\title{
Paradigma de la feminidad en los comienzos del siglo XXI
}

Carmen Secades*

Cuando planteo el paradigma, me propongo una recorrida por el arte y la literatura, revisando los modelos asignados a la mujer en la historia de la humanidad.

En este recorrido observo que a las mujeres se las representa, antes de describirlas o hablar de ellas y mucho antes que ellas mismas hablen.

Las Diosas pueblan el Olimpo de ciudades sin ciudadanas, la virgen, reina en los altares, donde ofician los sacerdotes, Marianne encarna a la República Francesa, cuestión viril. Todo lo inunda una mujer imaginada, imaginaria e incluso fantasmal.

Intento construir un paradigma que me permita captar algo de una organización sexuada, con ritos, donde a la mujer se la separa y se la integra, es virtuosa o prostituta, adorna, sin cuerpo, o permite el placer.

La Literatura tambien asigna roles que sintetizan la moral de cada época "La mujer es una esclava que es preciso entronizar" (Balzac) alimentándola de flores y perfumes.

Los hombres celebran la Musa, exaltan la Madona, mientras las sociedades cantoras, los coros licenciosos, y la expresión popular desvisten a " $\mathrm{La}$

* Psicóloga e Terapeuta Sexual. Membro da Asociación Argentina de Sexologia y Educacion Sexual - A.A.S.E.S.

Recebido em 15.01.01 
Señorita Flora" y examinan sus aptitudes para "obtener su diploma de puta". ¿Donde se ubica la mujer descripta desde el arte y la literatura, deseada, construída, segmentada? Un espeso manto de imágenes cubre su tierra y enmascara su rostro.

La mujer es definida por filósofos, juristas, médicos, moralistas, pedagogos: definida por su lugar y sus deberes.

Escribe Rousseau en su libro V en relación a los deberes: "Dar placer, ser útil, hacerse amar y honrar por ellos, criarlos de jóvenes, cuidarlos de mayores, aconsejarlos, consolarlos, hacerles agradable y dulce la vida"...

En la Edad Media "Las mujeres se unen en matrimonio a quienes oran, trabajan y combaten y a ellos sirven"...

No hay duda que el contenido de estos deberes se modifica con los siglos. En nombre de la utilidad social, se invita a las mujeres del siglo XIX y sobre todo a las del XX a salir de sus casas para servir y extenderse en la sociedad entera alejándose del gineceo y la casa victoriana.

Pero... ¿la utilidad social, en que sociedad? : Una mujer inca, una mujer azteca, una ona, una esquimal están en la misma sociedad que una cortesana, una geisha o una trabajadora inglesa?

La globalización económica de hoy, precedida por el pensamiento universal de las décadas pasadas, no se ha consumado en el aspecto social. No es lo mismo ser mujer cuando se carga una lata llena de agua durante cinco kilómetros en algún lugar de Africa, que cuando se entabla un interminable juicio de divorcio para decidir quién se queda con el yate. No es lo mismo acusar de acoso sexual al presidente de USA, que presentarse en una comisaría de los suburbios de Buenos Aires, a denunciar una violación y menos aún, si es inmigrante ilegal, iletrada o seropositiva.

Es que los cortes que hablan de género, como los que hablan de clases sociales, son cortes transversales. Y las sociedades, son verticales. A veces, la unicidad del discurso hace pensar en la unicidad del fenómeno. Pero operan en distintos niveles lógicos, así, la definición de los problemas y de las soluciones que son tales en Beverly Hills, ni siquiera son comprensibles para las mujeres de las favelas brasileñas.

Es cierto que en cada sociedad, en cada grupo aceptado como un siste$\mathrm{ma}$, se han producido cambios.

La mujer tiene acceso a la educación, produce, se quiebran las barreras materiales, lentamente deviene en persona.

De la doncella a la niñita desconocida. ¿Cómo se sostiene? ¿Quién la contiene? ¿ Donde habrá quedado el perfume de las flores?...

Toda una serie de errores y cegueras forman una historia de obstáculos que los prejuicios oprimen en la conciencia.

Ello, se debe, a que se hunden las raíces en un episteme común, un paradigma, que proviene de los hombres que dicen "nosotros" y hablan de "Ellas" y "Ellas" ¿qué dicen ellas?, la historia de nosotras las mujeres, proviene del acceso a la palabra y de nuestro esfuerzo por entrar en escena, 
una escena que aún hoy, no nos permite ser del todo y, transcurre en la añoranza del perfume de las flores y la exigencia del sistema.

Hoy las mujeres hemos podido acceder a una identidad personal y a un reconocimiento público.

En esta escalera nuestra voz depende de la alfabetización; el acceso a la educación; el autodominio de nuestra sexualidad; ¿ es esto cierto? $\mathrm{O}$ aún hoy continuamos transitando las fronteras fluctuantes entre lo permitido y lo prohibido.

En la personalización de lo femenino el concepto del género crece sobre todo en estos dos últimos siglos, debido principalmente al impulso feminista, movimiento que nos permite: dejar de ser viudas de guerra, Reinas o Damas, instrumentos indispensables de matrimonios u ornamentos de las fiestas.

La corte del gran Rey es un universo sexuado donde las mujeres tienen su rol recompensado por la mirada del memorialista..

Con la Revolución Francesa surge el amor romántico y la relación entre los sexos como un motor de la historia; de su equilibrio depende el de las sociedades; pero al asimilar a la mujer a la naturaleza signada por el varón, que oscila entre dos polos, maternal o erótico y los hombres a la cultura, no se hace otra cosa que repetir el modelo predominante.

Mientras las paredes de la Sorbona se cubren de frescos femeninos y se positivisa la historia en las universidades, la puja por lo público y lo privado le impone la conquista de ambos mundos en una busqueda denodada que garantice su identidad la que se afianza a partir de los estudios de género. Mientras que la conciencia de género no irrumpe en todos los países al mismo tiempo, se relaciona con las políticas imperantes y las raices de los pueblos.

El género que desde lo descriptivo y relacional se coloca en los modos vinculares entre los sexos, es producto de una construcción social.

Luego de años de pensar y sentir diferente creo hoy que deberíamos: desconstruir.

El final de siglo marca el momento preciso y nos invita a un cuestionamiento histórico: "Hacia la equidad en la diferencia" y la diferencia aspira a ser algo mas que el eco de los resultados; el planteo de los problemas y los interrogantes.

Ha llegado la hora de decir qué quisiéramos ser y cómo deberíamos ubicarnos en la historia.

Una historia que se inscribe desde la Antiguedad hasta fin del siglo XX en la determinación de nuestra esencia, como mujeres, que no puede terminar de resolverse desde un discurso especular, que a veces inmoviliza, y que a la vez ofrece resistencias, pero que continúa en movimiento y ofrece cambios.

Y esa especularidad del discurso entraña a su vez otra admonición, este espejo está quebrado, y entonces su imagen no sólo no es suya, sino del otro/a, !además está fragmentada! 
Así las mujeres operamos en realidad como muchas especies, muchas naturalezas en un único aspecto, las hay destinadas a la procreación, las hay destinadas al servicio, las hay destinadas al placer. No se espera, más aún se prohibe, que todos estos roles tengan una única protagonista.

$\mathrm{Y}$ es en realidad desde los hombres y las mujeres que estos roles se separan.

En la mayoría de los grupos jerárquicos animales, un macho monopoliza la gran mayoría de la actividad reproductiva. No toda, pero si gran parte. En los mamíferos, el macho puede, o no, alimentar a la cría. Por su propia estructura, la hembra entendida como función no puede cesar, las hembras ejercen una poderosa elección, en muchos casos determinante en el éxito reproductivo del macho.

Si el macho de nuestra especie conserva estas características, al edificar sobre su hembra algo a su imagen y semejanza, entonces construye una hembra fragmentada, donde, necesariamente debería haber una mujer íntegra.

La respuesta especular (Soy como tu) implica una negación. (No soy como tú) y entonces, construir un hombre (en quien) no es ta hombre.

¿Puede tener que ver esta confusión con el rol de sometimiento que se asigna a la mujer? Si miro lo que creo que debe ser un hombre y no veo un hombre, necesariamente lo acuso de haber fallado, y lo condeno a pagar esa culpa dejándose guiar y, paradójicamente, dejándose salvar.

Y lo extraordinario es que cuando se acepta la hora de la redención, la redención de ambos, (reflejo y reflejado) lo que se ofrece es la profundización de la segmentación, la oportunidad de ser como tú, y no la aceptación de que no soy como tú.

Pensemos en el masivo acceso de las mujeres a la industria durante la segunda guerra mundial. No fue fruto de una decisión, sino de la necesidad: los hombres estaban en el frente. Sus lugares -lugares de hombresquedaban vacios. Así, se permitió a las mujeres, ocupar este lugar, el supuesto paso adelante de la mujer, puede entenderse en realidad como remarcar las cadenas: estaban allí porque los hombres no podían.

Lo que vino después fué diferente; pero confundir ese manotazo desesperado desde el lugar tanático de la especie, que ocupado en matar, permitió al mas erotizado ocupar espacios vacantes, como un paso adelante, puede llevarnos a perpeturar la mecánica por la cual la mujer es en función del hombre, y según las necesidades de este se construirá; tanto el hombre como ser social, o como espacio individual.

Es desde esta situación, o mejor, desde la imaginería de esta situación, que se operan los cambios. ¿Cuáles son los cambios?. ¿Cuáles son las herencias, las transmisiones familiares y culturales, los modelos que se vehiculizan en la Educación, la Religión y el Derecho?.

¿Cuáles son los puntos de inflexión, las rupturas que hoy necesitamos para garantizar nuestra evolución? Quienes los sostienen desde la economía, la política o las costumbres?. 
Al comparar los diferentes períodos históricos observaremos que cada uno nos devuelve una mirada diferente, con sus lineas de fuerza y sus acentos específicos que nos determinan y nos ubican sin una relación de continuidad.

En nuestra América latina, ha incidido la colonización en la relación sexo y raza, diferente a los EEUU donde el feminismo fue decididamente antiesclavista; al de las mujeres del mundo oriental o el continente africano.

Cada continente podría reescribir su propia historia, ni el feminismo, ni la representación de la femeneidad son valores universales, se impone una doble mirada sobre lo que ya construimos y sobre lo que aún nos queda por construir en nuestra propia historia.

Aún quedan muchos huecos en nuestro paisaje, lo que explica, sin disculparlo la desigualdad en que suelen ser tratadas las mujeres en los diferentes sectores del planeta, la dispersión de la investigación y de nuestras propias redes de comunicación las que, podrían facilitar el surgimiento de otra historia en el marco real de las relaciones entre los hombres y las mujeres, entre las mujeres con las mujeres y los hombres con los hombres, con iguales y divergentes y hasta contradictorios modos de ser en el mundo.

¿Podremos lograr la unidad de nosotras las mujeres fuera del lenguaje articulando: sexo y clase, sexo y raza desde nuestros orígenes para apoyarnos en una construcción que rescate nuestra igualdad como seres humanos libres, donde la diferencia nos posibilite el placer de la realización, sin mandatos, y a partir del análisis del camino recorrido?

Una constante interrogación nos dará a conocer como es a lo largo del tiempo la construcción de nuestros saberes, de los poderes, de la práctica cotidiana, en las ciudades, en el campo, en el trabajo, en la familia, en lo público y lo privado, recreando nuestros lugares y delimitando nuevas esferas de funcionamiento.

Existe como punto de partida: una dominación masculina y por lo tanto una subordinación femenina en el horizonte visible de la historia. El sueño nostálgico y revolucionario de las primeras feministas americanas, que hoy concluye en avanzados estudios de género, creó un punto en que la reflexión se impone. ¿Continúa hoy vigente la dominación masculina? Podemos decir: es muy variable en sus modalidades, lo que no significa ausencia de poder de las mujeres, mas bien sugiere una reflexión acerca de la articulación de estos poderes, en un vínculo de igualdad creativa, en una verdadera redimensión del ser persona, donde se pueda integrar el goce y el deber, donde lo privado se autorice y revalorice y lo público se humanice para permitir la evolución de ambos: los hombres y las mujeres como fundantes de nuevos agrupamientos familiares y tejidos sociales donde las mujeres dejemos definitivamente de ser agentes de un sistema al cual contribuimos desde lo cotidiano y repetimos en nuestros hijos como algo asignado, que nos fue "dado" otorgado, con lo que garantizamos su perpetuidad. 
Porque es imprescindible esta lectura. La persona no como una entidad aparte, que recibe, procesa y elabora lo que le llega de su entorno separado, sino la de un ser humano constituído en, y con, ese entorno.

Hablar de mujer sin hablar de familia, sociedad, nación, es como hablar de dedo, un dedo no es comprensible sin la mano, y la mano misma es la explicación de todo lo que esa mano acaricia toca y retiene.

No es posible hablar de liberación femenina en una sociedad prisionera.

Suponer que el papel asignado a la mujer en las mayoría de las sociedades ha sido una elección de un grupo, es negar la otra posibilidad. Que esas sociedades existen como tales porque tienen tantos compartimientos y roles que hacen que la sociedad sea lo que es. Los avances en la legislación para la mujer lo que hacen proclamando auxiliarle, es profundizar la segmentación. Cualquier intento de igualar sin cambiar, equivale a controlar pequeñas oscilaciones en un sistema mayor. Algo así como permitir a nuestros hijos levantarse tarde un sábado a condición de que madruguen el resto de la semana. El sistema es y sigue siendo el mismo.

La tecnología posibilita nuevas formas de comunicarnos, trasmite sensaciones y recuerdos: Los de hoy y los de ayer como cimientos, unidos en el tiempo, rescatando los valores escenciales: el amor, la confianza, el conocimiento, la libertad de las mujeres y los hombres, incluyendo el placer y sin la necesidad de nombrar la igualdad como derecho porque ya lo es por si en la esencia misma de nuestra propia historia.

Este recorrido por la historia nos va develando a través de los siglos los ejes que atravesaron la construcción del rol de género, el que como Uds. han podido observar fue modelado a partir de las caracteristicas particulares de cada época.

¿Cuál es entonces el modelo de mujer para el próximo milenio?

Elaborarlo desde la mujer es parte del mecanismo especular, donde cada quien se considera aislado y decide en sí y para sí.

Esta construcción parcial olvida, que reelaborar un género es reelaborar el otro, pues no son comprensibles el uno sin el otro o los otros, y en verdad existen por su sinérgia, por la comunión, a veces perversa y no siempre conciente.

El siglo que termina nos consolida en la capacidad de elegir y ser elegidas: se nos otorga el derecho al voto, a disponer de los bienes heredados, a la maternidad - paternidad compartida, a organizarnos, a profundizar en los estudios de género a partir de las cátedras de la Mujer en nuestras universidades, etc.

Tenemos voz y podemos ser escuchadas.

Muchas bibliotecas contienen nuestros libros. Me interrogo y las/los interrogo ¿Cómo siente y se siente la mujer en los comienzos del III Milenio?

¿Puede ser libre, elegir ser feliz, compartir amar, gozar, delimitar su territorio en cualquier esfera tanto sea pública o privada? 
Si bien es cierto que las políticas económicas determinan en este difícil caminar la vida, $i$ podemos las mujeres al final del siglo concluir con el modelo especular que fundó nuestra lucha para compartirla y desde la voz esbozar a corazón abierto que sentimos y como sentimos? Nuestro derechos compartidos con nuestros compañeros/ras de vida restituyendo las diferencias.

La era del espejo parece llegar a su fin. Porque como ocurre siempre con los espejos, despues de la maravilla del descubrimiento, comienzan a agotarse sus posibilidades. Un espejo es un espejo, no un largavistas, ni un oráculo, ni un modelo. Una vez que nos vimos en él, que nos reconocimos, observaremos nuestra coordinación y nuestro aspecto, el viaje de autodescubrimiento debe, necesariamente, pasar por otro lugar.

Tal vez ello sea posible si miramos al otro/otra como semejante/ par/ pareja.

Rescatamos la diferencia en nuestra esencia de la femeneidad que no responde solo a la fisiología sino tambien en la posibilidad de pensarnos desconstruyendo lo que no nos permita ser libres, para facilitar la construcción de un mundo diferente.

Sensaciones y recuerdos: Los de hoy y los de ayer unidos en el tiempo, rescatando los valores escenciales, el amor, la confianza, el conocimiento, la libertad, la creación, nuevos modelos sin el sin razón nihilista de la existencia, nuevos caminos para acercarnos al placer. 